\title{
Early Childhood Caries Experience of Children from Poor Families Living Below and Above Poverty Line
}

\author{
Camila Faria Carrada ${ }^{1,2}(\mathbb{D}$, Maisa Costa Tavares $1(\mathbb{0}$, Andreia Maria Araújo Drummond $3,4 \oplus$, Nagila

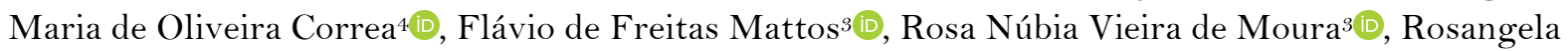 \\ Almeida Ribeiro ${ }^{5}\left[\right.$, Saul Martins Paiva ${ }^{1}[0$
}

\footnotetext{
'Department of Child and Adolescent's Oral Health, School of Dentistry, Federal University of Minas Gerais, Belo Horizonte, MG, Brazil.

${ }^{2}$ Department of Paediatric Dentistry, School of Dentistry, School of Medical Sciences, Juiz de Fora, MG, Brazil.

${ }^{3}$ Department of Social and Preventive Dentistry, School of Dentistry, Federal University of Minas Gerais, Belo Horizonte, MG, Brazil. ${ }^{4}$ Department of Dental Public Health, School of Dentistry, Federal University of Vales do Jequitinhonha e Mucuri, Diamantina, MG, Brazil.

${ }^{5}$ Department of Social and Paediatric Dentistry, School of Dentistry, Federal University of Juiz de Fora, Juiz de Fora, MG, Brazil.
}

Correspondence: Maisa Costa Tavares, Antônio Carlos Avenue, 6627, Department of Child and Adolescent's Oral Health, School of Dentistry, Belo Horizonte, MG, Brazil. 31270-901. E-mail: maisactavares@gmail.com

Academic Editor: Ana Maria Gondim Valença

Received: 10 March 2021 / Review: 17 May 2021 / Accepted: 08 July 2021

How to cite: Carrada CF, Tavares MC, Drummond AMA, Correa NMO, Mattos FF, Moura RNV, Ribeiro RA, Paiva SM. Early childhood caries experience of children from poor families living below and above poverty line. Pesqui Bras Odontopediatria Clín Integr. 2021; 21:e2 10057. https://doi.org/10.1590/pboci.2021.155

\begin{abstract}
Objective: To evaluate the role of poverty and its related factors on early childhood caries (ECC) experience among deprived children. Material and Methods: This population-based cross-sectional study surveyed 418 children aged one to six years enrolled in Brazilian public preschools from an area of the country known for its high social deprivation. Intraoral examination of children evaluated dental caries experience (dmft). Parents/caregivers answered a questionnaire with sociodemographic indicators. Family income was dichotomized into below or above poverty line. Data analysis used Chi-square test, MannWhitney test, and Multivariate Logistic Regression analysis $(\mathrm{p}<0.05)$. Results: Predisposing variables for an increased chance of ECC were: age group 3-4 years (OR: 4.89; 95\% CI: 2.32-10.31), age group 5-6-years (OR: 5.60; 95\% CI: 2.60-12.04), being part of families living below poverty line (OR: 1.88; 95\% CI: 1.043.38 ) and having mothers with less than nine years of schooling (OR: 2.86; 95\% CI: 2.77-7.14). Children from families living below poverty line presented higher $\operatorname{dmft}(2.9+3.8 ; \mathrm{p}=0.001)$ and untreated dental caries (d component) $(2.7+3.7 ; \mathrm{p}=0.002)$. Conclusion: ECC in a poor population was influenced by indicators of social deprivation. The poorest of poor children from mothers with less years of schooling were at higher risk.
\end{abstract}

Keywords: Dental Care for Children; Dental Caries; Poverty; Socioeconomic Factors. 


\section{Introduction}

Early childhood caries (ECC) is a disease with high prevalence in many countries, especially developing ones [1,2]. According to the International Association of Paediatric Dentistry, ECC is defined as the presence of at least one decayed, missing, or filled (due to dental caries) surface, in any primary tooth, in a child aged 6 years or younger [3]. In the latest epidemiological survey of oral health in Brazil [4], at 5 years of age, 53.4\% of Brazilian children had experienced dental caries in primary dentition. The etiology of dental caries includes biological, behavioural, and psychosocial factors [5]. Thus, it is an important public health problem strongly associated with political, cultural, educational, economical, and social conditions [6].

Inequalities in oral health challenge oral health promotion strategies [7]. Poverty increases health disparities between individuals [1,2]. Oral health standards of different groups in the Brazilian population express the social and economic organization of the country [8]. In Brazil, social exclusion, living and working conditions determine different epidemiological patterns [9] and the association between oral health status and poverty raises an important study subject.

Vale do Jequitinhonha is one of the poorest regions in Brazil (human development index of 0.615). It is in the southeast area of the country and is known as "The Valley of Poverty" [10]. In Vale do Jequitinhonha, $20.31 \%$ of children are extremely poor, $51.60 \%$ are poor and $74.25 \%$ are vulnerable to poverty [11]. Understanding individual factors involved in the ECC process allows identifying individuals and families at high risk of the disease and subsidizes the adequate planning of oral health promotion and care strategies aimed at those even more vulnerable [7]. The aim of this study is to assess the role of poverty and its predisposing factors on ECC in Brazilian children.

\section{Material and Methods}

Ethical Aspects and Sample

The study was approved by the Human Research Ethics Committee of the Universidade Federal dos Vales do Jequitinhonha e Mucuri (CAAE 69613117.1.0000.5108). All subjects consented to participate, and their mothers signed a written informed consent form.

This cross-sectional study included children enrolled in public preschools and their parents/caregivers in Diamantina, a city known as the door to Vale do Jequitinhonha, Brazil. It has an estimated population of 45,880 inhabitants and six public preschools distributed throughout the city [10]. All the schools in the urban area of Diamantina participated in the study. The families of all children enrolled in the schools were invited to participate, but only the ones that returned the informed consent participated.

The study's inclusion criteria were children aged between one and six years, regularly enrolled in preschools, and one parent/caregiver who lived with the child at least $12 \mathrm{~h}$ per day [12-14]. Parents/caregivers with cognitive changes that made it impossible to understand the issues addressed in the questionnaire were excluded.

Sample size was calculated considering 5\% error, 95\% confidence level (CI) and $43.7 \%$ prevalence rate of ECC [15]. Minimum sample size was estimated at 382 preschoolers, to which $20 \%$ was added to compensate for possible losses, giving a total sample of 458 children.

\section{Data Collection}

Two previously trained and calibrated examiners conducted children oral exams at preschools. Training allowed the discussion of diagnostic criteria. A specialist in pediatric dentistry provided the 
theoretical framework and coordinated this step, instructing examiners. Calibration was conducted in two stages. First, 10 children were clinically evaluated to assess and discuss diagnostic criteria. Second, 20 children were examined twice by the same examiners, observing a one-week interval between each examination. Kappa coefficients for inter-examiner (in relation to the gold standard) and intra-examiner agreement were 0.8 and 0.81 , respectively.

World Health Organization methodology for oral health surveys and national criteria from the Brazilian National Oral Health Survey were adopted: clinical examination was performed in a room with natural light; by visual inspection; and teeth were cleaned and dried with gauze prior to dental examination $[3,16]$. Data collection was carried out from March to October 2017, including clinical children's examinations and the interview of one parent/caregiver using a structured questionnaire.

\section{Individual Variables}

Dental caries was assessed according to WHO's criteria for dmft index [17]. The index provided four variables for ECC assessment: (a) Dental caries experience = mean dmft; (b) Untreated dental caries = decayed component of dmft; (c) Treated dental caries = filled component of dmft. Dental caries experience was dichotomized into $\mathrm{dmft} \geq=1$ and $\mathrm{dmft}=0$.

Socioeconomic and demographic characteristics were assessed through the interview, guided by a questionnaire, to parents/caregivers. It included information regarding mothers' years of schooling, marital status, situation in the labor market, poverty status, household overcrowding, and children's characteristics (sex, age and skin color). Poverty status was dichotomized into families living below poverty line and families living above poverty line, according to the World Bank (WB) [10,18]. It refers to income and consumption levels in lower-middle income (\$ 3.20/day) and upper-middle income economies (\$ 5.50/day), such as Brazil. The sum of US $\$ 1.90 /$ day establishes the international line of extreme poverty.

\section{Data Analysis}

Data analysis was performed using the Statistical Package for Social Sciences program (SPSS for Windows, version 21.0, SPSS Inc., Armonk, NY, USA). Kolmogorov-Smirnov test demonstrated non-normal distribution of the sample. Descriptive analysis (absolute and relative frequencies) was performed for all variables. Multivariate Logistic Regression analysis was performed. Effect was estimated using odds ratio (OR) and 95\% confidence intervals. Differences between families below poverty line and above poverty line, in relation to ECC (untreated caries, treated caries and caries experience) were tested using Mann-Whitney test. Significance level was set at $5 \%(\mathrm{p}<0.05)$.

\section{Results}

A total of 418 children participated in the study and their mothers were interviewed. Dental caries experience was identified in 215 children $(51.3 \%)$ and $30 \%$ of the sample concentrated $86.2 \%$ of all diagnosed dental caries. In different age groups mean dmft index and mean figures of untreated dental caries (decayed component of $\mathrm{dmft})$ were, respectively: $1.01(\mathrm{SD}=2.59)$ and $0.97(\mathrm{SD}=2.52)$ for children aged 1 to 2 years, $2.35(\mathrm{SD}=3.42)$ and $2.25(\mathrm{SD}=3.32)$ for children aged $3-4$ years and $3.38(\mathrm{SD}=4.12)$ and $3.03(\mathrm{SD}=3.98)$ for children aged 5 to 6 years. Frequencies of individual characteristics of the sample are summarized in Table 1. Children aged 3-to-4-years were the most frequent $(43,6 \%)$ and girls accounted for $50.0 \%$ of the sample. Among mothers, $51.7 \%$ presented less than 9 years of study. Most children lived in families (61.8\%) below poverty line. 
Table 1 displays logistic regression results considering dental caries experience and independent variables. Variables that increased children's chances of being affected by ECC were: being 3 to 4 years old (OR: 4.89; 95\% CI: 2.32-10.31), being 5 to 6 years old (OR: 5.60; 95\% CI: 2.60-12.04), living in families below poverty line (OR: 1.88; 95\% CI: 1.04-3.38) and having mothers with less than nine years of schooling (OR: 2.86; 95\% CI: 2.77-7.14). On the other hand, children from mothers with more than 12 years of schooling presented a lower chance of being affected by ECC (OR: 0.36; 95\% CI: 0.19-0.88).

Table1. Distribution of frequency and analysis of the odds ratio of caries experience, demographic and socioeconomic variables in children aged 1 to 6 years.

\begin{tabular}{|c|c|c|c|c|c|}
\hline Variables & $\mathbf{N}(\%)$ & $\begin{array}{c}\text { dmft }=\mathbf{0} \\
\mathrm{N}(\%)\end{array}$ & $\begin{array}{c}\mathbf{d m f t} \geq \mathbf{1} \\
\mathrm{N}(\%)\end{array}$ & OR $(95 \% \mathrm{CI})$ & p-value* \\
\hline \multicolumn{6}{|l|}{ Child's Characteristics } \\
\hline \multicolumn{6}{|l|}{ Sex } \\
\hline Male & $209(50.0)$ & $97(46.41)$ & $112(53.59)$ & 1 & \\
\hline Female & $209(50.0)$ & $107(51.19)$ & $102(48.81)$ & - & \\
\hline \multicolumn{6}{|l|}{ Age } \\
\hline $1-2$ years old & $78(18.98)$ & $60(76.90)$ & $18(23.10)$ & 1 & \\
\hline $3-4$ years old & $184(43.06)$ & $83(45.10)$ & $101(54.90)$ & $4.89(2.32-10.31)$ & $<0.001$ \\
\hline $5-6$ years old & $156(37.96)$ & $60(38.50)$ & $96(61.50)$ & $5.60(2.60-12.04)$ & $<0.001$ \\
\hline \multicolumn{6}{|l|}{ Skin Color } \\
\hline White & $81(19.37)$ & $38(46.91)$ & $43(53.08)$ & 1 & \\
\hline Non-white & $337(80.63)$ & $161(47.77)$ & $176(52.22)$ & - & \\
\hline \multicolumn{6}{|l|}{ Socioeconomic Status } \\
\hline \multicolumn{6}{|l|}{ Mother's Years of Schooling } \\
\hline$>12$ years & $53(12.69)$ & $37(69.82)$ & $16(30.18)$ & 1 & \\
\hline $10-12$ years & $141(33.73)$ & $66(46.80)$ & $75(53.20)$ & - & \\
\hline$\leq 9$ years & $217(51.91)$ & $94(43.32)$ & $123(56.68)$ & $2.86(2.77-7.14)$ & 0.022 \\
\hline None & $7(1.67)$ & $2(28.57)$ & $5(71.43)$ & - & \\
\hline \multicolumn{6}{|l|}{ Marital Status } \\
\hline Living with partner & $257(61.48)$ & $128(49.80)$ & $129(50.20)$ & 1 & \\
\hline Living without partner & $161(38.52)$ & $70(43.48)$ & $91(56.52)$ & - & \\
\hline \multicolumn{6}{|c|}{ Situation in the Labor Market } \\
\hline Employee/Retired & $303(72.49)$ & $144(47.53)$ & $159(52.57)$ & 1 & \\
\hline Unemployed & $115(27.51)$ & $55(47.83)$ & $60(52.17)$ & - & \\
\hline \multicolumn{6}{|l|}{ Poverty Status } \\
\hline Above poverty line & $160(38.28)$ & $93(58.13)$ & $67(41.87)$ & 1 & \\
\hline Below poverty line & $258(61.72)$ & $105(40.70)$ & $153(59.30)$ & $1.88(1.04-3.38)$ & 0.036 \\
\hline \multicolumn{6}{|l|}{ Household Overcrowding } \\
\hline Up to 4 people & $247(59.09)$ & $116(47.00)$ & $131(53.00)$ & 1 & \\
\hline More than 4 people & $171(40.91)$ & $87(50.90)$ & $84(49.10)$ & - & \\
\hline
\end{tabular}

OR: Odds Ration; *Multivariate Logistic Regression.

Table 2 shows the relationship between the ECC and families' poverty status. Families below poverty line presented higher means of untreated caries $(2.7 ; \mathrm{SD}=3.7)$, treated caries $(0.2 ; \mathrm{SD}=0.8)$, and dental caries experience $(2.9 ; \mathrm{SD}=3.8)$ when compared with families above poverty line.

Table 2. Relationship between early childhood caries (ECC) and the poverty status of families of children aged 1 to 6 years.

\begin{tabular}{|c|c|c|c|}
\hline \multirow[b]{2}{*}{ ECC } & \multicolumn{2}{|c|}{ Poverty Status } & \multirow[b]{2}{*}{ p-value* } \\
\hline & $\begin{array}{c}\text { Below Poverty Line } \\
\text { Mean (SD) }\end{array}$ & $\begin{array}{c}\text { Above Poverty Line } \\
\text { Mean (SD) }\end{array}$ & \\
\hline Untreated Dental Caries & $2.7 \pm 3.7$ & $1.7 \pm 3.1$ & 0.002 \\
\hline Treated Dental Caries & $0.2 \pm 0.8$ & $0.1 \pm 0.6$ & 0.041 \\
\hline Dental Caries Experience & $2.9 \pm 3.8$ & $1.8 \pm 3.2$ & 0.001 \\
\hline
\end{tabular}

*Mann-Whitney test. 


\section{Discussion}

Literature shows that socioeconomic inequalities are important factors that affect oral health since early childhood [2,19-21]. Inequalities in oral health are still relevant even in the context of lowering caries prevalence identified in recent decades [21] and have been described as major challenges in public health [22]. Therefore, studies investigating the relationship between social determinants and dental caries distribution in populations provide useful strategies to guide policies towards reducing oral health inequalities [21,22].

Previous studies in the Brazilian population-related low income to higher sugary foods intake [23], lower access to health services [20] and worse oral hygiene standards [23]. These factors mediate the effect of material deprivation on the increased risk of dental caries [21]. Thus, measures that reduce socioeconomic disparities are essential to improve oral health, which is intrinsically associated with social and economic conditions [6]. In this study, children from families living below poverty line were almost twice as likely to have ECC compared to children from families living above poverty line.

At a young age, the main causes of tooth decay are beyond control of children, making mothers' individual factors very relevant [7]. Maternal education is a strong predictive variable for ECC, considered as strong as family income [24]. While family income represents the power to purchase goods, maternal education represents the ability to provide assistance, including regular dental visits and lower sugar intake. These are protective factors for ECC [25]. The present study showed that mothers with years of schooling $\leq 9$ were almost three times more likely to have children with ECC when compared to mothers with years of schooling $>12$. Although the ways in which mother's education affects children's dental caries is not fully understood, some interpretations may help explain them [2]. Such interpretations should go beyond the recognition that low maternal schooling may be linked to low economic status, or even that mothers with less years of schooling do not receive information concerning essential care for their children's oral health [26]. When the population receives guidance on oral health, it is often unable to interpret them, making oral health literacy necessary [27]. Parental low oral health literacy affects professional-caregiver communication, is decisive in adherence to health care measures, and may result in oral health problems such as ECC [28]. Access to information and the way it is transmitted must be considered when approaching mothers regarding guidelines on children's oral health. It is important to choose appropriate communication strategies.

Older children (3 to 4-year-old and 5 to 6-year-old) presented a higher chance of ECC when compared with younger children ( 1 to 2 years of age). It could be explained by the longer presence of teeth in the oral cavity, which results in longer exposure to a cariogenic environment [26] and a socially vulnerable life. It should be noted that the dmft index, used for the diagnosis of dental caries in children, does not assess the initial lesions of the disease. Therefore, study results must be interpreted with caution. On the other hand, the use of the dmft index allows a comparison between the caries experience (mean dmft) of the studied population and that found in the latest Brazilian epidemiological survey [4]. At 5 years of age, a Brazilian child had an average of 2.43 teeth with caries experience, with a predominance of the decayed component, which was responsible for more than $80 \%$ of the index [4]. In this study, mean $\mathrm{dmft}$ was 3.38 .

The present study identified that children from families below poverty line presented a higher ECC mean when compared to children from families above poverty line. According to the European Union, income poverty refers to deprivation of material resources, such as money, food, or housing [29]. Severe material deprivation is related to increased susceptibility to the development of serious adverse health consequences for children, including ECC [2,30]. High sugar consumption is the main risk factor for ECC [7,23,24]. Studies have shown that sugar access and consumption are higher in low-resource settings. High-sugar meals are 
cheaper and easily accessible [31], even when people are deprived of the essentials for a minimum standard of well-being and life [29].

Children from families below poverty line presented more treated teeth mean when compared to children from families above poverty line. It suggests that the poorest among poor children may have had equitable access to dental care and restorative treatment. Equity in access to oral health care seeks to recognize differences in living and health conditions and people's needs, considering that the right to health goes through social differences and must follow diversity [22]. Equity in access to dental services in the studied population may result from the local presence of the Dental School of a public University. As part of the Brazilian Unified Health System, it provides free dental care to the community. However, children from families below poverty line also presented higher untreated teeth mean when compared to children from families above poverty line. It suggests that although they have access to restorative care, oral health promoting, and preventive initiatives were not effective.

The World Bank's international definition of poverty line [18] was adopted in this study. The global rate of extreme poverty dropped to $9.2 \%$ in 2017, from $10.1 \%$ in 2015 [32]. However, global poverty is expected to increase in 2020, as the cumulative effects of the COVID-19 pandemic set high human and economic costs in the future [33].

The relationship between inequalities in oral health and poverty differ between countries and regions. It occurs according to historical, political, and economic environments that shape income inequality at different levels of social organization [32]. There is a need to investigate factors that connect income inequality to oral health outcomes within different populations. They would help to understand and address the social drivers of inequalities in oral health. This study provides evidence on the relationship between ECC experience and socioeconomic factors among low-income families with children from 1 to 6 years of age. Instead of comparing children and families from distinctively different socioeconomic levels, it identified differences in ECC prevalence within a population closely distributed around poverty line. Even between children and families from different degrees of low socioeconomic level, family income and mother's years of schooling still determined ECC risk. It was also possible to observe a large number of cases of the disease concentrated in a small group of individuals. It is suggested that a portion of this population remains excluded from the benefits of collective health measures aimed at oral health.

Although the study sample included only children in public schools, $85 \%$ of the 1 to 6-year-old local children were enrolled in public schools at baseline, reinforcing the validity of our findings. The cross-sectional nature of the study is a limitation, for it does not allow to establish over time relationships. However, this study is an important tool to identify risk and protection indicators to be included in future longitudinal assessments.

Our findings have major implications for oral health policy and planning regarding the role of socioeconomic inequalities on ECC prevalence among poor children. Knowledge of individual determinants for ECC development, such as maternal education and poverty status, should guide policies aimed at families below poverty line and in higher deprivation. Changing people's behaviour requires changing their environment [34]. The environment can turn healthy decisions into easy ones. And policies directed to environmental contexts should be emphasized [22]. Community involvement and research approaches giving voice to those traditionally excluded population are pivotal aspects to consider in the future. The reduction of inequalities in oral health must be a goal when aiming to simultaneously promote health and social justice. 


\section{Conclusion}

It is concluded that early childhood caries experience in children from a population with different levels of social deprivation was strongly associated to family income and mothers' years of schooling. The poorest of poor children from mothers with less years of schooling were at higher risk of ECC.

\section{Authors' Contributions}

\begin{tabular}{|c|c|c|}
\hline $\mathrm{CFC}$ & (D) https://orcid.org/0000-0002-3173-2904 & Formal Analysis, Writing - Original Draft and Writing - Review and Editing. \\
\hline MCT & (iD) https://orcid.org/0000-0003-2 108-8569 & Writing - Original Draft and Writing - Review and Editing. \\
\hline AMAD & (iD) https://orcid.org/0000-0003-4161-5602 & Conceptualization, Validation and Data Curation. \\
\hline NMOC & (iD https://orcid.org/0000-0001-7476-0844 & Investigation and Data Curation. \\
\hline FFM & (iD) https://orcid.org/0000-0002-6052-2762 & Conceptualization, Validation, Writing - Review and Editing and Visualization. \\
\hline RNVM & (iD) https://orcid.org/0000-0002-8947-2797 & Conceptualization and Writing - Review and Editing. \\
\hline RAR & (iD) https://orcid.org/0000-0001-6472-5965 & Writing - Review and Editing and Supervision. \\
\hline SMP & (iD) https://orcid.org/0000-0002-3968-1638 & $\begin{array}{l}\text { Conceptualization, Methodology, Writing - Review and Editing, Supervision and Project } \\
\text { Administration. }\end{array}$ \\
\hline
\end{tabular}

\section{Financial Support}

This study was supported by the Universidade Federal de Minas Gerais, the Universidade Federal dos Vales do Jequitinhonha e Mucuri, the Coordenação de Aperfeiçoamento de Pessoal de Nível Superior - Brasil (CAPES) - Finance Code o01, the Research Foundation of the State of Minas Gerais (FAPEMIG) and the National Council for Scientific and Technological Development (CNPQ).

\section{Conflict of Interest}

The authors declare no conflicts of interest.

\section{Data Availability}

The data used to support the findings of this study can be made available upon request to the corresponding author.

\section{References}

[1] Folayan MO, Alade M, Adeniyi A, El Tantawi M, Finlayson TL. Association between maternal socioeconomic factors, decision-making status, and dental utilization by children with early childhood caries in sub-urban Nigeria. J Public Health Dent 2020; 80(4):288-96. https://doi.org/10.1111/jphd.12383

[2] Folayan MO, Tantawi ME, Aly NM, Al-Batayneh OB, Schroth RJ, Castillo JL, et al. Association between early childhood caries and poverty in low and middle income countries. BMC Oral Health 2020; 20(1):8. https://doi.org/10.1186/s12903-019-0997-9

[3] Tinanoff N, Baez RJ, Diaz Guillory C, Donly KJ, Feldens CA, McGrath C, et al. Early childhood caries epidemiology, aetiology, risk assessment, societal burden, management, education, and policy: Global perspective. Int J Paediatr Dent 2019; 29(3):238-48. https://doi.org/10.1111/ipd.12484

[4] Brasil. Ministério da Saúde. Projeto SB Brasil 2010: Nota Para A Imprensa; Brasília (DF): Ministério da Saúde, 2010. Available from: http://www.idisa.org.br/img/File/SA-UDE\%20BUCAL-NotaParaImprensa-28dez2010\% 20\%282\%29.pdf. [Accessed on July 7, 2020]. [In Portuguese].

[5] Pitts NB, Baez RJ, Diaz-Guallory C, Donly KJ, Feldens CA, McGrath C, et al. Early Childhood Caries: IAPD Bangkok Declaration. Int J Paediatr Dent 2019; 29(3):384-6. https://doi.org/10.1111/ipd.12490

[6] Ortiz AS, Tomazoni F, Knorst JK, Ardenghi TM. Influence of socioeconomic inequalities on levels of dental caries in adolescents: A cohort study. Int J Paediatr Dent 2020; 30(1):42-9. https://doi.org/10.1111/ipd.12572

[7] Priesnitz MC, Celeste RK, Pereira MJ, Pires CA, Feldens CA, Kramer PF. Neighbourhood determinants of caries experience in preschool children: a multilevel study. Caries Res 2016; 50(5):455-61. https://doi.org/10.1159/000447307

[8] Silva JV, Machado FCA, Ferreira MAF. Social Inequalities and the oral health in Brazilian Capitals. Cien Saude Colet 2015; 20(8):2539-47. https://doi.org/10.1590/1413-81232015208.12052014

[9] Passos JS, Araújo TM, Gomes Filho IS, Cruz SS. Life conditions and oral health: a theoretic conceptual approach of social inequalities. Rev Baiana Saúde Pública 2011;35(1 Suppl):138-50.

[10] Brasil. Instituto Brasileiro de Geografia e Estatística (IBGE). Síntese de indicadores sociais: uma análise das condições de vida da população brasileira. $2017 . \quad$ Available from: https://biblioteca.ibge.gov.br/visualizacao/livros/liv 101459.pdf. [Accessed on July 7, 2020]. [In Portuguese]. 
[11] Programa das Nações Unidas para o Desenvolvimento. Atlas de Desenvolvimento Humano no Brasil. 2010. Available from: http://www.atlasbrasil.org.br/2013/pt/perfil_m/diamantina_mg. [Accessed on July 7, 2020]. [In Portuguese].

[12] Clementino MA, Gomes MC, Pinto-Sarmento TCA, Martins CC, Granville-Garcia AF, Paiva SM. Perceived impact of dental pain on the quality of life of preschool children and their families. PLoS One 2015; 10(6):e0130602. https://doi.org/10.1371/journal.pone.0130602

[13] Gomes MC, Neves ÉT, Perazzo MF, Paiva SM, Ferreira FM, Granville-Garcia AF. Toothache and non-clinical individual and school factors in five-year-old children: multilevel analysis. Braz Dent J 2018; 29(6):569-75. https://doi.org/10.1590/0103-6440201802077.

[14] Viana VS, Fernandez MS, Nunes FS, Vieira IS, Martins-Filho PRS. Parental caregivers perceptions of oral healthrelated quality of life in children with autism spectrum disorder. J Dent Health Oral Disord Ther 2020; 11(5):132-37. https://doi.org/10.15406/jdhodt.2020.11.00531

[15] Corrêa-Faria P, Paixão-Gonçalves S, Paiva SM, Pordeus IA, Marques LS, Ramos-Jorge ML. Association between developmental defects of enamel and early childhood caries: a cross-sectional study. Int J Paediatr Dent 2014; 25(2):103-9. https://doi.org/10.1111/ipd.12105

[16] World Health Organization. Oral Health Surveys: Basic Methods. 4th. ed. Geneva: WHO; 1997.

[17] World Health Organization. Oral Health Surveys. 5th ed. Geneva: WHO. 2013. Available from: http://www.who.int/oral_health/publications/9789241548649/en/. 2013. [Accessed on March 12, 2018]. [In Portuguese].

[18] World Bank. Measuring the Real Size of the World Economy: The Framework, Methodology, and Results of the International Comparison Program (ICP). Washington, DC: World Bank, 2013.

[19] Aida J, Matsuyama Y, Tabuchi T, Komazaki Y, Tsuboya T, Kato T, et al. Trajectory of social inequalities in the treatment of dental caries among preschool children in Japan. Community Dent Oral Epidemiol 2017; 45(5):407-12. https://doi.org/10.1111/cdoe.12304

[20] Carreiro DL, Souza JGS, Coutinho WLM, Haikal DS, Martins AMEBL. Acesso aos serviços odontológicos e fatores associados: estudo populacional domiciliar. Cien Saude Colet 2019; 24(3):102 1-32. https://doi.org/10.1590/1413-81232018243.04272017

[21] Ardenghi TM, Piovesan C, Antunes JLF. Inequalities in untreated dental caries prevalence in preschool children in Brazil. Rev Saude Publica 2013; 47(3 Suppl):129-37. https://doi.org/10.1590/So034-8910.2013047004352

[22] Sheiham A, Alexander D, Cohen L, Marinho V, Moysés S, Petersen PE, et al. Global oral health inequalities: task group - implementation and delivery of oral health strategies. Adv Dent Res 2011; 23(2):259-67. https://doi.org/10.1177/0022034511402084

[23] Carvalho JC, Silva EF, Vieira EO, Pollaris A, Guillet A, Mestrinho HD. Oral health determinants and caries outcome among non-privileged children. Caries Res 2014; 48(6):515-23. https://doi.org/10.1159/000360709

[24] Mafla AC, Moran LS, Bernabe E. Maternal oral health and early childhood caries amongst low-income families. Community Dent Health 2020; 37(3):223-8. https://doi.org/10.1922/CDH_00040Mafla06

[25] World Bank. Poverty headcount ratio at national poverty lines (\% of population). 2019. Available from: https://data.worldbank.org/indicator/SI.POV. NAHC. [Accessed on May 20, 2019].

[26] Moghaddam LF, Vettore MV, Bayani A, Bayat AH, Ahounbar E, Hemmat M, et al. The Association of Oral Health Status, demographic characteristics and socioeconomic determinants with Oral health-related quality of life among children: a systematic review and Meta-analysis. BMC Pediatr 2020; 20(1):489.

https://doi.org/10.1186/s12887-020-02371-8

[27] Firmino RT, Ferreira FM, Martins CC, Granville-Garcia AF, Fraiz FC, Paiva. Is parental oral health literacy a predictor of children's oral health outcomes? Systematic review of the literature. Int J Paediatr Dent 2018; 28(5):45971. https://doi.org/10.1111/ipd.12378

[28] Firmino RT, Martins CC, Faria LDS, Martins Paiva S, Granville-Garcia AF, Fraiz FC, et al. Association of oral health literacy with oral health behaviors, perception, knowledge, and dental treatment related outcomes: a systematic review and meta-analysis. J Public Health Dent 2018; 78(3):231-45. https://doi.org/10.1111/jphd.12266

[29] European Foundation for the Improvement of Living and Working Conditions. Europe 2020 indicators - poverty and social exclusion. 2020. Available from: https://ec.europa.eu/eurostat/statistics-explained/pdfscache/29306.pdf. [Accessed on April 10, 2020].

[30] Masumo R, Bardsen A, Mashoto K, Åstrøm AN. Prevalence and socio-behavioral influence of early childhood caries, ECC, and feeding habits among 6-36 months old children in Uganda and Tanzania. BMC Oral Health 2012; 12:24. https://doi.org/ 10.1186/1472-6831-12-24

[31] Ndekero TS, Carneiro LC, Masumo RM. Prevalence of early childhood caries, risk factors and nutritional status among 3-5-year-old preschool children in Kisarawe, Tanzania. PLoS One 2021; 16(2):e0247240. https://doi.org/10.1371/journal.pone.0247240

[32] World Bank. Purchasing Power Parities and the Size of World Economies: Results from the 2017 International Comparison Program. Washington, DC: World Bank; 2020.

[33] World Bank. Poverty and Shared Prosperity 2020: Reversals of Fortune. Washington, DC: World Bank; 2020. 
[34] World Health Organization. Equity, Social Determinants and Public Health Programmes. Blas E, Sivasankara Kurup A (Editors). Geneva: WHO; 2010. 